\title{
Design de interface gráfica: interpretação semiótica na composição dos elementos
}

\section{Graphical interface design: semiotic interpretation of the composition of elements}

\author{
Rosane de F. A. Obregon, Tarcisio Vanzin, Vânia R. Ulbricht
}

design gráfico, composição visual, semiótica

\begin{abstract}
Este artigo apresenta uma análise da página inicial da interface gráfica do Ambiente Virtual de Aprendizagem em Arquitetura e Design - AVA_AD, da Universidade Federal de Santa Catarina. Para tanto, apóia-se na Teoria Geral dos Signos proposta por Charles Sanders Peirce. Inicialmente, o texto apresenta a fundamentação teórica. Em seguida, apresenta a descrição do objeto em análise. Por fim, os elementos representativos da interface são interpretados de acordo com a teoria estudada, discutindo-se, inclusive, as correlações entre a composição gráfica e os conceitos de signo na perspectiva peirceana.
\end{abstract}

graphic design, visual composition, semiotic

This article presents an analysis of the graphic interface of the Virtual Learning Environment in Architecture and Design - AVA_AD of Federal University of Santa Catarina, initial home page. The analysis is based on the General Theory of Signs proposed by Charles Sanders Peirce. Initially, the text presents the theoretical foundation followed by a description of the object in question. This is followed by a description of the analyzed object. Finally, the significant elements of the interface are interpreted according to the theory studied. Correlations between graphic composition and the concepts of sign in Peirce's perspective are also presented.

\section{Introdução}

Para a teoria semiótica, tudo pode ser percebido como linguagem, inclusive e especialmente as interfaces gráficas, na medida em que essas participam diretamente de processo de comunicação. Assim, a linguagem de interface pode ser comparada como a linguagem natural, tanto em sua função comunicativa quanto em sua estrutura, como um sistema em evolução composto de elementos e inter-relacionamentos.

Rheinfrank e Evenson (1996) aprofundam essa analogia mostrando que a linguagem natural consiste de palavras e regras gramaticais, sendo usada para criar formas de expressão significativas. Da mesma forma, a linguagem de interface consiste na composição de elementos de design, visando a comunicação com usuário. Como a linguagem natural, a linguagem de interface é usada para criação ou geração textual e para a interpretação ou leitura. O conhecimento dos leitores sobre a linguagem natural compõe a base necessária para a interpretação das mensagens linguísticas. O conhecimento da linguagem de interface também serve como base para a interpretação e interação como uma interface que, neste caso, é o Ambiente Virtual em Arquitetura e Design - AVA_AD.

Em interfaces gráfico-digitais para a relação homem/computador, os elementos da linguagem servem como mediadores entre as intenções do sujeito humano e as reações do computador. Essa é uma relação plenamente significante, porque não há comandos diretos. As ferramentas digitais e as ações digitais atuam com uma lógica própria que difere das ações humanas, mas os signos da interface buscam oferecer ao usuário uma relação amigável, na qual elementos que sugerem a ação humana são apresentados como chaves de acionamento das ações digitais. Assim, os elementos da interface atuam necessariamente como signos, porque são sinais perceptíveis ou formas de expressão que detêm significação, estando associados a outras coisas que representam (Perassi, 2005).

O design da interface necessita ser um signo plenamente coerente com o conteúdo que pretende representar e interagir. A interface cria a identidade visual do sistema ou produto digital, 
sendo considerada como um conjunto de elementos que apresentam a organização das informações e as ações do usuário.

É necessário que a composição da interface seja estruturada e apresentada de acordo com padrões ergonômicos e de usabilidade, considerando suas funções de comunicação e interação homem/computador. Isso envolve preceitos expressivos, estéticos ou sintáticos, e comunicativos, significativos ou semânticos, além de outros aspectos interativos e funcionais.

Uma interface digital, por suas características multimídia e hipermídia afeta diferentes sentidos do usuário e promovem diversas ações, compondo um todo perceptivo-interativo. O contato e a interação do usuário com uma interface digital requer e, também, promove o desenvolvimento de processos cognitivos de aprendizagem. A Teoria Semiótica aplicada ao estudo de interfaces permite predizer o processo de cognição e significação proposto. Isso importa aos designers e a outros profissionais envolvidos na composição de ambientes virtuais de comunicação e aprendizagem, porque amplia suas possibilidades de projeção quanto à significação da interface e sua comunicação interativa com o usuário.

\section{O estudo dos signos e da significação}

A Semiótica é um campo de estudos que objetiva estudar os signos, sistemas de signos e a "vida" dos signos na sociedade. Há aproximadamente dois mil anos que se conhece a disciplina Semiótica (Eco, 1980). Contudo, o seu desenvolvimento da forma como a entendemos hoje em dia só se deu a partir dos trabalhos do filósofo norte americano Charles Sanders Peirce (18391914) e do linguista suíço Ferdinand de Saussure (1857-1915).

O objetivo da Semiótica é a investigação de todas as linguagens possíveis. Mas, além disso, propõe a investigação de qualquer fenômeno como produção de significação e sentido. Para Santaella (1996), a Semiótica se propõe a ver o mundo como linguagem, mas não se refere apenas à língua verbal falada ou escrita, inclui todos os tipos de linguagens, inclusive, a linguagem dos surdo-mudos, da dança, e da moda, entre outros.

Um signo é qualquer coisa que está no lugar de outra coisa para alguém sob determinados aspectos ou capacidades (Peirce, 1997). Isto é, qualquer marca ou sinal percebido e associado ao pensamento, compondo conceitos, informações e comandos, entre outras possibilidades de significação e ação. Sem o signo, a comunicação seria muito pobre, porque dependeria da apresentação direta dos objetos aos quais se deseja referir (Sebeok, 1994). Nesse caso, pensamentos e sentimentos seriam incomunicáveis, porque não poderiam e ainda não podem ser diretamente apresentados aos interlocutores em geral. Pensamentos e sentimentos são expressos por signos vocais, faciais e gestuais, entre outros.

"De modo geral, texto, signo, símbolo ou representação, todos esses termos designam sinais perceptíveis ou formas de expressão que detêm significação, porque são associados a outras coisas e as representam" (Perassi, 2005, p.27). Há mensagens ou signos fortemente codificados e predominantemente semânticos ou simbólicos, que são investidos diretamente na comunicação. Há também mensagens ou signos com fraca codificação, que são predominantemente expressivos, estéticos ou icônicos e investidos prioritariamente na expressão. O campo semântico ou simbólico determina ideias ou cognições e busca o entendimento. O campo expressivo, estético ou icônico determina sensações, promovendo sentimentos ou afetos (Perassi, 2005).

A materialidade dos objetos percebidos ou a imagem do objeto percebida como externa à mente expressa as características materiais de sua composição. Esta corporeidade da imagem indica formas, cores e tonalidades, configurando seu campo icônico-expressivo ou estético. A mesma imagem é relacionada e passa a representar outras coisas por meio de codificações estabelecidas por convenções, por hábitos ou por analogias, compondo seu campo semântico. Ao se relacionar e representar outra coisa, a imagem de uma palavra, de um objeto ou de um sinal qualquer atua como um signo para a mente ou consciência que a percebe.

\section{A semiótica peirceana}

Ao considerar um objeto percebido por uma mente ou consciência como representação de uma outra coisa diferente do próprio objeto, Peirce (1977) indica o signo como um composto de três elementos que foram denominados como: (1) signo ou representamen, termos que denominam o objeto percebido; (2) referente ou objeto, termos que indicam a coisa representada, e (3) 
interpretante, termo que se refere à ideia produzida pela presença do signo na mente que o percebe.

A percepção de um signo cria na mente que o percebe um signo equivalente ou modificado a partir de sua imagem. Isso caracteriza o processo de "ação do signo", que foi indicado por Peirce (1977) como "semiose". É o próprio pensamento como processo continuado que consiste na semiose, partindo de uma percepção que provoca ideias e, por sua vez, essas ideias iniciais promovem outras ideias subsequentes e, assim por diante, tendendo ao infinito. $O$ segundo signo, que é a ideia gerada na mente, é denominado interpretante do signo. A coisa ausente que foi representada pelo signo é denominada como objeto do signo (figura 1).

Figura1: Interpretação gráfica do modelo de signo triádico

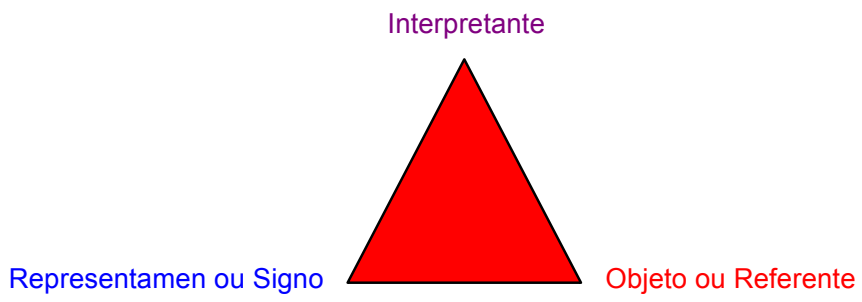

Para Peirce (1977), a semiose estabelece no processo de percepção e interpretação do objeto ou fenômeno pela mente ou consciência, compondo uma fenomenologia em três etapas: 1primeiridade, 2- secundidade, e 3- terceiridade.

Caso o objeto não seja percebido, sua existência não é reconhecida pela mente. Por isso, primeiramente, o signo se caracteriza como um evento subjetivo. Quando a mente toma consciência do objeto externo, configura-se um segundo elemento, que é reconhecido como objetivo. A ideia mediadora entre a sensação do primeiro e a percepção do segundo é o terceiro elemento, estabelecendo a mediação cultural entre o elemento sentido e o elemento percebido.

As categorias constituem o fundamento básico para a compreensão da semiótica na perspectiva peirceana, porque são como conceitos gerais no domínio do conhecimento. Para Santaella (1996), a primeiridade é em sua essência o presente, o imediato, é uma sensação nova não podendo ser articuladamente pensada, porque quando é pensada já perdeu sua primazia característica. Por sua vez, a secundidade é aquilo que é e se opõe à vontade da mente apesar de estar presente nas ideias. Na terceiridade se desenvolve a ação inteligente ou a elaboração cognitiva em função do que é segundo e do que é primeiro.

Ao perceber um objeto externo, a mente sente as características dessa aparição que é vivenciada como primeiridade. Ao perceber que os estímulos the são externos e partem de um objeto que existe e resiste à sua vontade, a mente experimenta a secundidade. Ao comparar as sensações vivenciadas com experiências e conhecimentos já vividos anteriormente, nomeando as sensações, o objeto percebido ou representamen e o objeto representado ou referente, de acordo com as circunstâncias culturais, a mente estabelece a experiência de terceiridade.

\section{Semiótica e interface gráfica hipermídia}

Nadin (1988) é o autor de um dos primeiros trabalhos a sugerir a aplicação de conceitos de Semiótica em Design de Interfaces. Andersen (1997), cuja primeira edição de seu trabalho remonta a 1990, sugere a aplicação de Semiótica não só em Design de Interfaces, estendendo sua aplicação às áreas de Programação, de Análise e de Projeto de Software. Em um trabalho recente, Leite e Souza (1997) descrevem um framework para o processo de Design de Linguagens de Interface, ancorado na Teoria Semiótica da Produção Sígnica, que foi formulada por Umberto Eco, com base no conceito peirceano de signo.

Entre outras possibilidades, o estudo semiótico parte do reconhecimento dos elementos e das relações expressivas no âmbito categórico de primeiridade, que são promotores de sensações e sentimentos, porque estabelecem a ordem sintática ou estética da interface gráfica. Isso ocorre 
por meio da expressividade de sons, de movimentos, de cores, de formatos, de linhas e de planos, entre outros elementos visíveis. A partir dessa observação, o estudo procura reconhecer as composições e interações dos elementos sintáticos que estabelecem no âmbito categórico de terceiridade os elementos e as relações semânticas. Isso ocorre por meio de relações figurativas ou linguísticas, que representam músicas, imagens, palavras e outros símbolos. Todos os efeitos previstos, sejam no âmbito das sensações primeiras ou das compreensões terceiras, são possíveis devido à secundidade tecnológica do computador, que estabelece a hipermídia gráfica por meio de seus recursos que emitem e codificam os índices luminosos na tela do vídeo e os índices sonoros, previamente codificados e emitidos pelas caixas acústicas.

\section{Descrição da página inicial da interface AVA_AD}

Ao observar a imagem a seguir (figura 2) percebe-se uma figura retangular composta por linhas paralelas e perpendiculares e, também, por planos, por figuras e por palavras. No conjunto predominam a cor azul, branca e ocre-dourada.

Figura 2: Interface do AVA_AD (www.ava_ad.ufsc.br).

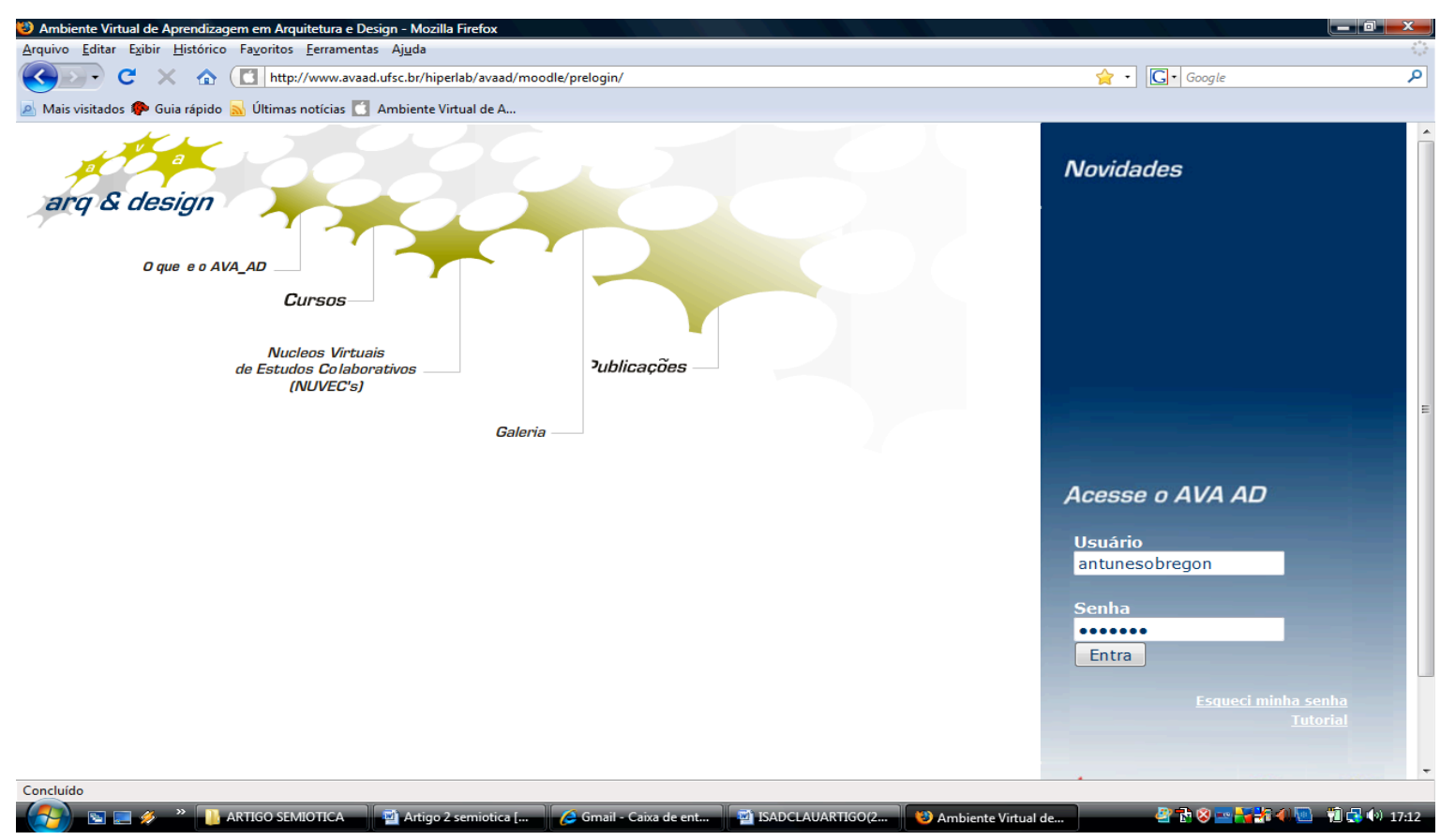

O limite superior e o limite inferior da figura são demarcados por duas linhas escuras que apresentam sobre sua forma ícones coloridos e letras brancas. O limite lateral à direita do observador é demarcado por uma linha azul clara com pontos escuros nas extremidades e um ponto escuro no centro. O limite lateral à esquerda do observador é sugerido pelas linhas escuras que limitam a figura e pelo limite de outros elementos da composição, uma vez que não pode ser percebido sobre o fundo branco.

Imediatamente abaixo da linha escura que limita a parte superior da figura, aparece um retângulo azul claro, predominantemente horizontal e, sobre sua forma, também, há ícones coloridos, palavras e linhas brancas. Os lados menores desse retângulo azul claro são cerca de três vezes mais largos do que a linha escura que limita a figura, mas os lados maiores coincidem com a extensão da linha.

No lado direito do observador, justaposto ao retângulo azul claro horizontal superior, aparece na vertical outro retângulo, cujo preenchimento varia de um tom azul escuro para um tom azul claro. Sobre esse retângulo também aparecem palavras e três retângulos brancos na horizontal. Dois desses retângulos são maiores, ocupam quase dois terços da largura do retângulo vertical. $\mathrm{O}$ terceiro é menor e aparece justaposto ao retângulo maior branco inferior.

Ao lado esquerdo do observador, abaixo do retângulo azul claro horizontal e justaposto ao retângulo azul vertical aparece uma área retangular branca que abriga um conjunto de figuras 
estreladas que variam em tonalidade de cinza e dourado e também em tamanho. Há ainda palavras compondo expressões sobre esse fundo branco: "arq \& design"; "o que é o AVA_AD"; "cursos"; "núcleos virtuais e estudos colaborativos (NUVECs)"; "galeria"; "publicações". Excetuando a primeira, todas as expressões são ligadas por finas linhas horizontais e verticais às figuras estreladas.

Há uma linha azul muito sutil, que demarca fim da área branca retangular, sob essa linha pode ser percebida uma barra estreita e clara que apresenta uma palavra em seu limite à esquerda do observador.

A figura como um todo se mostra como um conjunto de elementos visualmente expressivos. Parte desses elementos, como palavras e ícones, indica uma clara função semântica ou simbólica. Outra parte dos elementos, entretanto, como planos, linhas e figuras cumprem especificamente a função sintática, poética ou estética, compondo e estruturando o campo visual que abriga os elementos simbólicos.

\section{Descrição da página inicial da interface $A V A \_A D$}

A composição gráfica cumpre a função de organizar visualmente a interface e, considerando-se a posição do observador da interface, há um plano maior no lado esquerdo de quem percebe e outro plano menor do lado direito. Na parte superior destes dois planos, estão as faixas claras e escuras que são ocupadas por signos referentes ao navegador de internet. No plano inferior observa-se a outra faixa escura com os signos da barra de status do navegador e da barra de tarefas do sistema operacional. Além das palavras e dos ícones que são claramente elementos semânticos, há um conjunto de figuras estreladas, no plano branco à esquerda do observador. Em princípio, a função dessas figuras é predominantemente ilustrativa.

A ordem geométrica e plana das formas retangulares predomina na composição da interface. Porém, a organização do conjunto de figuras estreladas rompe a ordenação plana e geométrica, porque provoca um efeito de espacial e orgânico no plano maior branco à esquerda do observador.

O sentido espacial ocorre devido à variação ordenada de tamanho das figuras estrelares, que aumentam da esquerda para direita e de cima para baixo. Decorre também da variação tonal entre cinza e dourado, sendo que os tons dourados que são mais contrastantes com o fundo, aparecem nas ou nas partes das figuras que estão mais abaixo no conjunto. A variação tonal na área interna das figuras reforça o sentido espacial, sugerindo também variações de volume. O contorno das figuras estrelares propõe uma configuração orgânica, apesar das figuras serem plenamente configuradas por elementos geométricos.

\section{Elementos simbólicos da composição}

A página inicial da interface é ocupada por diferentes palavras, que são elementos semânticos ou simbólicos por excelência. Há diversos ícones característicos do sistema operacional "Windows Vista". Isso é evidenciado, inclusive, pelo próprio símbolo da "Microsoft" na versão "Windows Vista", que aparece na extremidade esquerda da faixa escura, que delimita a parte inferior da composição gráfica. Há outros símbolos visíveis, que são relacionados a softwares específicos. Além disso, a própria "barra de ferramentas", na qual aparecem ícones e palavras, bem como os visores e os campos de preenchimento de informações são elementos simbólicos. Essa indicação se justifica, porque as funções de barras e campos são previamente convencionadas, de acordo com os procedimentos de utilização de interfaces de computador. A maior parte das palavras que aparecem na composição gráfica da primeira página da interface consta nos dicionários, sendo comumente utilizadas em ambientes digitais. Todavia, a expressão "arq \& design" e a sigla "AVA_AD" não são comumente conhecidas e só podem ser devidamente compreendidas por leitores ou usuários que foram previamente informados de suas significações.

Além dos elementos tipicamente simbólicos, há outros que se constituem como signos e assumem valor semântico por analogia visual, ao instigar a mente a relacioná-los com sensações decorrentes de experiências anteriores, as quais foram provocadas por outros estímulos.

Primeiramente, toda a composição da primeira página da interface é sentida na mente como um grande ícone ou uma grande imagem. Em seguida, a composição passa a ser percebida como um conjunto de índices luminosos coloridos. Isso acontece na medida em que a mente se dá conta da existência externa de uma fonte luminosa, que é a tela iluminada do vídeo. Por analogia visual, a mente reconhece que a imagem é composta por linhas, planos e figuras, porque os elementos percebidos se assemelham a outros, que também são identificados e codificados pela 
cultura com os mesmos nomes. Um processo semelhante permite associar as impressões produzidas na superfície plana da tela do vídeo com sensações de volume e de espaço e, também, permite a associação das figuras estreladas com formas orgânicas, que se assemelham às imagens de neurônios como são culturalmente conhecidas.

Do ponto de vista poético-afetivo, há uma ideia de perspectiva ou espacialização, em que uma parte da imagem parece apresentar um fluxo crescente numa direção descendente, promovendo os sentidos de espaço e movimento. A organização do conjunto das figuras estreladas e o ritmo proposto pelas variações e contrastes tonais sugerem que algumas figuras estão iluminadas ou estão se iluminando, enquanto outras se mostram sem contraste ou apagadas. Essa sugestão dinâmica, que decorre da variação tonal, pode representar as sinapses neuronais, por analogia ou semelhanças aproximativas.

A maneira como os elementos prioritariamente expressivos ou icônicos são compostos e organizados promove associações. No caso da imagem plana e estática da primeira página da interface gráfica, a composição e a organização dos elementos passam a representar ou significar figuras, como linhas, planos, estrelas ou neurônios, e relações dinâmicas e espaciais, como sinapses. A partir dos elementos expressivos ou icônicos, são compostos os signos icônicos ou as representações visuais por analogia entre o imediatamente percebido e o previamente conhecido e memorizado.

\section{Interpretação da imagem de acordo com a teoria Semiótica}

Ao ser percebida como signo triádico, a primeira página da interface em estudo, AVA_AD, abriga três elementos. O primeiro elemento é a representação ou composição gráfica percébida como representamen ou signo. O segundo elemento é a imagem mental da representação gráfica, juntamente com outras referências que compõem o conjunto interpretante do signo na mente que o percebe. O terceiro elemento é formado pelo conjunto de objetos ao qual o signo se refere ou representa, considerando-se que representa um conjunto de sinais que caracterizam e denotam as páginas de internet.

A representação gráfica da primeira página da interface aqui apresentada (figura 2) faz referência à própria interface e, também, a todas as interfaces gráficas desse mesmo tipo ou semelhantes. Além de outras referências, como a interface "Windows Vista" e outras associações que não são tratadas aqui.

A percepção da representação gráfica anterior (figura 2) suscita na mente que a percebe uma outra imagem ou o segundo signo que também a representa, porque é seu interpretante. Além de suscitar diversas associações passíveis de gerar outros interpretantes em extensa semiose. Essa tríade proposta pela representação gráfica como signo triádico é representada pela imagem a seguir (figura 3).

Figura 3: Signo triádico adaptado ao objeto em estudo.

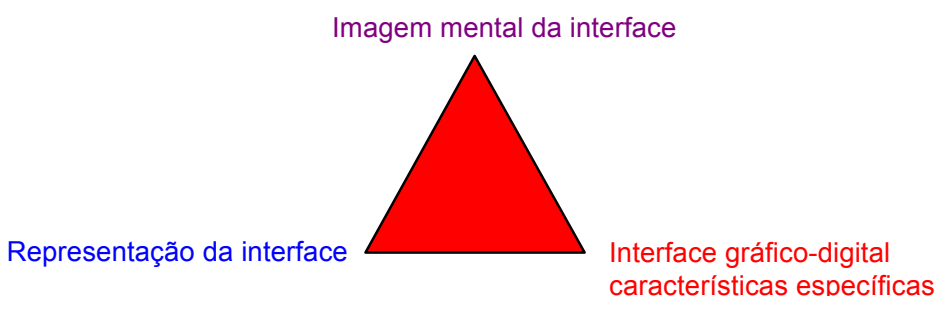

Impressa sobre papel ou percebida diretamente na tela de vídeo, a imagem da primeira página da interface AVA_AD é um signo, cujo objeto ou referente é a própria interface como um todo. Ao perceber a imāgem gráfica, a mente produz o segundo signo mental que é o interpretante do signo percebido. Cada um dos elementos expressos na imagem percebida, também, é percebido como um signo específico da representação ou do signo geral. Os interpretantes, produzidos a partir de cada signo em particular, implicam diretamente na composição dos interpretantes do signo geral. Por isso, é possível interpretar as significações de elementos específicos e suas interações na composição dos interpretantes relacionados ao signo geral. 
No âmbito da "primeiridade", destaca-se a sensação, onde a impressão do todo predomina sobre as partes e, o usuário não discrimina atentamente os seus elementos componentes. Em um segundo momento, aparece na mente do usuário uma mancha luminosa e predominantemente azul e branca, suscitando sensações mais dinâmicas e espaciais na parte central da imagem. O reconhecimento por parte da mente de que essas perturbações são determinadas por estímulos externos caracteriza a "secundidade", como processo de reconhecimento de um outro. $\mathrm{Na}$ secundidade, a subjetividade da "primeiridade" é reconhecida como índices luminosos de uma fonte externa. O reconhecimento da fonte luminosa como sendo a tela do vídeo de um computador e todas as outras associações simbólicas que relacionam percepções e palavras determinam a "terceiridade". A aparição da imagem e da significação da página da interface na mente usuáriointérprete acontece de forma interativa entre as três categorias, a "primeiridade", a "secundidade" e a "terceiridade".

Como foi assinalado anteriormente, as sensações e os sentimentos determinados pelos aspectos icônicos, estéticos ou poéticos, da imagem são vivenciados na mente, já no momento em que se estabelece a "primeiridade". Os símbolos ou significados, que caracterizam mais especificamente o campo semântico, são produtos da "terceiridade", porque decorrem dos significados culturais, que foram memorizados, compondo o repertório cognitivo da mente. Porém, a ampla e diversificada significação, que é proposta pela composição da primeira página da interface, decorre de uma profícua interação entre os sentidos poéticos e os significados simbólico-culturais.

Os efeitos cromáticos e os ritmos lineares caracterizam o campo poético. A ortogonalidade das linhas e dos planos paralelos e perpendiculares promove as sensações de ordenamento e o reconhecimento do plano, que demarcam a moldura da composição gráfica. Já a variação tonal no plano retangular vertical e azul, que aparece à direita do espectador, além da variação tonal e cromática e da variação de tamanho das formas estreladas, promove sensações espaciais e dinâmicas. Um efeito dinâmico e espacial é produzido justamente pela variação tonal do retângulo azul à direita do espectador. Do outro lado, a composição das formas estreladas faz com que o plano retangular branco à esquerda do espectador seja percebido como um campo espacial. Todavia, esses efeitos não são integrados entre si, mantendo uma rígida separação entre plano branco e o plano azul.

O retângulo vertical azul também aparece mais próximo do espectador, sugerindo estar mais à frente que o retângulo branco. Isso sugere que o acesso ao espaço hipermídia, representado pela área branca, depende da transposição da área azul, que se apresenta como pré-condição de entrada. Esse sentido é reforçado pelo convite proposto na frase "Acesse o AVA_AD", sobre o retângulo azul um pouco acima da localização dos espaços destinados à inserção dos dados "usuário" e "senha".

No retângulo branco, o sentido espacial é prejudicado pela proximidade entre o conjunto de formas estreladas e a moldura plana superior, que cumpre a função de "barra de ferramentas". A proximidade inibe o efeito espacial no retângulo branco, associando visualmente dois sentidos poéticos contraditórios, o sentido de plano geométrico, retangular, estático e horizontal da "barra de ferramentas" e o efeito espacial, rítmico e dinâmico do conjunto das formas estreladas.

Com relação aos aspectos tipicamente semânticos ou simbólicos, como foi dito anteriormente, a maior parte das palavras utilizadas faz parte do acervo oficial da língua portuguesa. A decodificação das expressões linguísticas que identificam a interface e a associação do conjunto de formas estreladas com uma rede de neurônios requerem do usuário algum conhecimento prévio sobre a interface. Todavia, por ser um espaço interativo, quando a página inicial é percebida e acessada por meio de um computador ligado à internet, a interface em estudo possibilita que o usuário obtenha as informações complementares que são necessárias, por meio de caixas de texto com conteúdo explicativo. As caixas de texto surgem quando as formas estreladas são acionadas pelo cursor do mouse. O conteúdo de cada caixa de texto é relacionado às expressões linguísticas que aparecem sobre o retângulo branco e que são ligadas por linhas finas paralelas e perpendiculares às formas estreladas.

\section{Considerações finais}

Neste texto, considera-se que o valor de uma informação ou mensagem é diretamente proporcional à sua capacidade de modificar o comportamento do receptor, seu procedimento físico, mental ou afetivo. Assim, os objetos visíveis são percebidos como imagens e podem ser 
interpretados ou lidos sob diversos enfoques. Entretanto, a organização dos elementos e sua significação constituem aspectos determinantes para a composição da representação, a partir da iconicidade dos elementos expressivos.

A semiótica peirceana oferece os conceitos necessários à compreensão da dinâmica entre pensamento, expressão e representação. Isso foi apresentado neste texto, a partir do conceito de signo triádico e das categorias fundamentais de "primeiridade", "secundidade" e "terceiridade". Assim, a expressão visual ou imagem gráfica da primeira página da interface AVA_AD foi descrita e interpretada, como representação ou signo da própria interface, no processo de comunicação com o espectador/leitor/usuário.

O processo interpretativo apresentou dois campos de significação, sendo um icônico, sintático ou poético, e outro simbólico ou semântico. Diante do vídeo do computador, esses campos são expressos por índices luminosos multicoloridos. $\mathrm{Na}$ imagem impressa os campos são expressos por índices pictóricos, também, multicoloridos. Nas duas situações, a luz incidente na tela do vídeo ou a luz refletida pela tinta de impressão permite a percepção visual do ícone colorido, que se apresenta como a imagem gráfica ou representação da interface AVA_AD.

A ampla significação e a comunicação da página com o espectador são decorrentes da interação entre o campo icônico-expressivo e o campo simbólico-semântico. Pois é a interação sintático-semântica ou icônico-simbólica que compõe as referências e promove os interpretantes. Nesse sentido, são percebidos dois aspectos interessantes na comunicação da página inicial da interface.

Já foi dito anteriormente que há uma incoerência poética na proximidade e no contato da figura composta por formas estreladas com a parte superior da moldura da página, porque a proximidade da moldura plana e geométrica conflita com o sentido dinâmico e espacial do conjunto estrelado. Isso caracteriza um aspecto interessante com relação ao campo icônico. O outro aspecto é relativo ao campo simbólico, porque antes que seja acionado algum "link" explicativo, os símbolos da página inicial são enigmáticos ou pouco esclarecedores, aparecendo como siglas ou promessas.

A expressão "arq \& design" compõe um logotipo, porque é apresentado como um ícone específico. Mas, apesar do símbolo "\&" e da palavra "design", a expressão como um todo não estabelece uma referência amplamente inteligível. A mesma situação acontece com a sigla "AVA_AD" que não é amplamente conhecida. No entanto, aparece um conjunto de promessas capazes de estimular a curiosidade do usuário comum. As expressões "o que é o AVA_AD"; "cursos"; "núcleos virtuais e estudos colaborativos (NUVECs)"; "galeria"; "publicações", e "novidades" representam promessas que incentivam o usuário a deslocar o cursor do mouse sobre a tela em busca de "links" que, como foi indicado anteriormente, provocam o aparecimento de "caixas de textos" com conteúdos explicativos.

Os usuários acostumados ao relacionamento com interfaces gráfico-interativas, por meio de computadores ligados à internet, irão reconhecer a plataforma "Windows Vista" e os ícones de programas conhecidos, comumente associados à dinâmica desse tipo de plataforma. Portanto, esse público ampliado por outros públicos adjacentes saberá também que a "navegação" no ambiente hipermídia, a partir dessa página inicial, depende de uma pré-inscrição e da obtenção de uma senha válida. Isso caracteriza a página inicial como signo expressivo-representativo de um ambiente restrito.

Por outro lado, mesmo o usuário acostumado com plataformas hipermídia, pode não dominar os códigos específicos dos ambientes virtuais de aprendizagem (AVA). Assim, terá dificuldades para compreender do que trata esse ambiente e também para associar as formas estreladas com neurônios e sinapses. A representação como um todo se mostra de maneira discreta e enigmática. Talvez, isso aguce a curiosidade do usuário, fazendo-o interagir na página com o cursor do mouse.

Para finalizar, o presente estudo possibilitou a descrição e a interpretação da página inicial da interface AVA_AD, considerando os pressupostos da teoria semiótica peirceana. $O$ processo interpretativo revelou uma representação que prima pela discrição, considerando tanto os elementos icônicos, com formas e cores discretas, quanto os elementos simbólicos pouco reveladores. A composição da página apresenta-se como um enigma, que deve ser descoberto por meio da interação com o usuário. Assim, justifica o sentido subjetivo, cognitivo e semiótico, que é proposto e ilustrado na representação de uma rede de neurônios. 


\section{Referências}

ANDERSEN, P. B. 1997. A theory of computer semiotics. New York: Cambridge University Press.

AVA_AD - Ambiente Virtual de Aprendizagem em Arquitetura e Design. Disponível em: $<w w w . a v a \_a d . u f s c . b r>$.

ECO, U. 1980. Tratado geral de semiótica. São Paulo: Perspectiva.

LEITE, J. C., SOUZA, C. S. 1997. A framework for the semiotic engineering of user interface languages. In: Lucena, C. J. P. (ed.), Monografias em ciência da computação. Rio de Janeiro: PUC-Rio.

NADIN, M. 1988. Interface design. Semiotica. v. 69, n. 3/4, p. 269-302.

PERASSI, R. L. S. 2005. Roteiro didático da arte na produção do conhecimento. Campo Grande, MS: EDUFMS, p.23-37.

RHEINFRANK, J., EVENSON, S. 1996. Design languages. In Winograd, T. (ed.). Bringing design to software, p. 63-80. New York: Addison-Wesley.

SANTAELLA, L. 1996. O que é semiótica. São Paulo: Brasiliense.

2002. Semiótica aplicada. São Paulo: Pioneira Thompson Learning.

SEBEOK, T. A. 1994. Signs: an introduction to semiotics. Toronto: University of Toronto Press.

\section{Sobre os autores}

Rosane de Fatima Antunes Obregon é Mestre em Engenharia e Gestão do Conhecimento e Doutoranda no Programa de Pós-Graduação em Engenharia e Gestão do Conhecimento/EGC, Universidade Federal de Santa Catarina/UFSC. Coordenadora de Curso do Centro Universitário do Maranhão e Pedagoga do Laboratório de Hipermída para a Aprendizagem-HiperLab/UFSC.

<antunesobregon@gmail.com>

Tarcisio Vanzin é Doutor em Engenharia de Produção pela Universidade Federal de Santa Catarina/UFSC. É professor Adjunto 4 na UFSC. É docente no Programa de Pós-Graduação Arquitetura e Urbanismo/PósArq e em Engenharia e Gestão do Conhecimento/EGC/UFSC ministrando as disciplinas de Produção Hipermídia, Sistema Multimídia, Cibersociedade, Cibercidade, Criatividade e Erros Humanos.

<tvanzin@yahoo.com.br>

Vânia R. Ulbricht é Doutora em Engenharia de Produção pela Universidade Federal de Santa Catarina/UFSC. Atua como pesquisadora na Université de Paris I (Pantheon-Sorbonne). É professora voluntária no Programa de Pós-Graduação em Engenharia e Gestão do Conhecimento/EGC/UFSC.

<ulbricht@floripa.com.br> 